\title{
Statin Use and Risk of Sepsis After Percutaneous Nephrolithotomy
}

\author{
Abdulrahman F. Alruwaily, MD, ${ }^{1,2}$ Brian H. Eisner, MD, ${ }^{3}$ Maggie J. Bierlein, MS, \\ Khurshid R. Ghani, MD, J. Stuart Wolf, Jr., MD, FACS,, Brent K. Hollenbeck, MD, MS, \\ and John M. Hollingsworth, MD, MS ${ }^{1}$
}

\begin{abstract}
Purpose: To examine the association between statin medication use and sepsis risk after percutaneous nephrolithotomy (PCNL).

Materials and Methods: Using medical claims data, we identified working-age adults with urinary stone disease who were treated with PCNL. Among this cohort, we determined which patients had a prescription fill for a statin agent that encompassed their surgery date. We then fitted logistic regression models to examine for differences in rates of postoperative sepsis between statin users and nonusers. In addition, we evaluated the frequency of nonfebrile urinary tract infections (UTIs) and intensive care unit (ICU) services utilization and hospital length of stay (LOS) as a function of statin use.

Results: During the study period, at total of 2046 patients underwent PCNL, 382 (18.7\%) of whom had a prescription fill for a statin agent preceding their surgery. The overall rate of sepsis in this population was $3.8 \%$. After adjusting for patient health status and sociodemographic factors, the rate of postoperative sepsis was comparable between statin users and nonusers (5.3\% vs 3.5\%, respectively; $P=0.105)$. In addition, UTI and ICU utilization rates did not relate to statin use ( $P>0.05$ for all associations). Adjusted hospital LOS was shorter among statin users, but the difference was clinically trivial (3.6 vs 4.1 days; $P=0.007)$.

Conclusions: Statin use is not associated with reductions in postoperative sepsis, nonfebrile UTIs, ICU utilization, or hospital LOS after PCNL. To increase the safety of PCNL, urologists will have to consider other processes of care (e.g., clinical care pathways).
\end{abstract}

\section{Introduction}

W ITH REPORTED STONE-FREE RATES ranging from 76\% to $85 \%$, percutaneous nephrolithotomy (PCNL) is considered the treatment of choice for patients with large renal calculi. ${ }^{1}$ Despite technologic advances that have increased the safety of the procedure, PCNL is still associated with measurable morbidity including postoperative sepsis, the consequences of which can be catastrophic. ${ }^{2,3}$ Rates of sepsis after PCNL are reported as high as $8 \%$, which is 20 times higher than other endourologic procedures. ${ }^{4-6}$ As such, the investigation of adjunctive therapies that may reduce the risk of sepsis after PCNL is warranted. Statins may be one such therapy.

Emerging data suggest that the benefits of statins extend beyond their lipid-lowering effects. Specifically, empiric work shows that these medications exhibit both anti-inflammatory and antioxidant properties, as well. ${ }^{7-9}$ Statins have been shown to blunt the first step in the activation of the cellular cascade of the immune system in reaction to microbial infection, thereby lowering levels of cytokines, tumor necrosis factor, and C-reactive protein-drivers of the sepsis response. ${ }^{10,11}$ To the extent that these properties can be leveraged to modulate the systemic immune response, statin use may have a role in the prevention of postoperative sepsis. ${ }^{12}$ Among different populations, statin use has been shown to be associated with lower rates of other types of infections, including respiratory, blood, and urinary infections. ${ }^{13-16}$ No study yet, however, has examined the infectious prophylaxis role of statin in patients undergoing PCNL.

To address this knowledge gap, we conducted an observational study using medical claims from working-age adults. After identifying patients with nephrolithiasis who were treated with PCNL, we determined those who were prescribed a statin medication preoperatively. We then

\footnotetext{
${ }^{1}$ Department of Urology, Divisions of Endourology and Health Services Research, University of Michigan Medical School, Ann Arbor, Michigan.

${ }^{2}$ Department of Surgery, College of Medicine, Al-Imam Muhammad Ibn Saud Islamic University (IMSIU), Riyadh, Saudi Arabia.

${ }^{3}$ Department of Urology, Harvard Medical School, Boston, Massachusetts.
} 
estimated the risk of postoperative sepsis, comparing rates between statin users and nonusers. Findings from our analysis serve to inform urologists who manage urinary stone disease on the utility of statin prophylaxis among PCNL patients.

\section{Materials and Methods}

\section{Data source}

For our study, we used Truven Health's MarketScan ${ }^{\circledR}$ Commercial Claims and Encounters Database (2002-2006). This database captures the healthcare utilization of an estimated 5.6 million working-age adults and their dependents with employer-sponsored benefit plans. Contained within these data are all inpatient and outpatient claims submitted on a beneficiary's behalf, including detailed prescription drug information, which was important, given our interest in statin use.

\section{Study population}

Through a previously described algorithm, we used International Classification of Diseases, Ninth Revision, Clinical Modification (ICD-9) diagnosis codes to identify adults 18 to 64 years of age with one or more claims for urinary stone disease. ${ }^{17,18}$ We then used relevant Current Procedural Terminology codes to identify the subset of patients who underwent PCNL at some point during the study interval. For study inclusion, we required that persons have continuous enrollment in a benefit plan for a minimum of 120 days before and 30 days after the index date for their surgical procedure. We excluded those enrolled in benefit plans from which Truven Health did not receive prescription drug claims in the 30 days before the procedure.

\section{Exposure}

We then used National Drug codes for 32 proprietary and generic statin medications to distinguish between patients prescribed statin therapy before PCNL and those who were not. ${ }^{19}$ We tracked statin use based on prescription fill dates and the number of days supplied. A patient was considered a statin user if he or she had a prescription fill for a statin agent, where the days supplied encompassed the procedure date and the 2 weeks before it. We chose a 2 -week period because the anti-inflammatory of statins have been observed within 2 weeks of treatment. ${ }^{20}$ For our primary analysis, patients who stopped their statin more than 90 days before the surgical procedure were classified as nonusers. Patients who were taking statins at some point between 90 days and 14 days of the index date were excluded from the study cohort because of possible residual effects of statin therapy.

\section{Outcomes}

Our primary outcome of interest for this study was the occurrence of sepsis after PCNL. We defined sepsis events using an ICD-9 code-based algorithm. Within the 30-day period after the procedure date, we said that a sepsis event occurred if a patient had a claim filed on his behalf with one or more of the following ICD-9 codes: 020.0x (septicemic), 038.xx (septicemia and its subtypes), 785.52 (septic shock), 790.7x (bacteremia), 995.91 (sepsis), 995.92 (severe sepsis), and 780.6 (fever of unknown origin).
In addition to the occurrence of sepsis, we measured a variety of secondary outcomes, including the occurrence of a nonfebrile urinary tract infection (UTI), the use of intensive care unit (ICU) services postoperatively, and hospital length of stay (LOS). UTIs were identified in the 30-day period after the surgery date using a previously described ICD-9 codebased algorithm. ${ }^{21}$ Hospital LOS was defined using patient admission and discharge status. ICU services use was determined through standard revenue codes from the facility claims filed within the 30-day surgical episode.

\section{Statistical analysis}

For our initial analytic step, we used $t$ tests and chi-square tests, where appropriate, to compare statin users and nonusers across a variety of sociodemographic and clinical factors. Specifically, we made comparisons based on patient age, sex, surgery setting (inpatient vs outpatient), employee classification (salaried $v s$ nonsalaried), employment status (full- $v s$ part-time), benefit plan type (comprehensive, preferred provider organization, health maintenance organization, pointof-service, or other noncapitated plan), residence within a metropolitan statistical area, and geographic region of residence based on the United States Census regions (Northeast, Midwest, South, or West).

Because a patient's baseline health may contribute to his or her sepsis risk, we assessed comorbidity using a modification of the Charlson index. ${ }^{22}$ In addition, we identified all the patients who had a medical claim filed for sepsis or a nonfebrile UTI within the 90-day window before the surgery date using the ICD-9 codes mentioned above. Further, we determined those patients who were prescribed antimicrobial therapy within 5 days of their procedure (but not including the day of the procedure, which reflects standard antibiotic prophylaxis).

After adjusting for the patient factors described above, we then used multiple logistic regression to evaluate the association between statin use and the occurrence of postoperative sepsis. We fitted similar models to assess the relationship between statin use and UTI and ICU utilization rates. Finally, we used multivariable Poisson regression to evaluate the relationship between hospital LOS and the use of statin therapy. We conducted all analyses using $\mathrm{SAS}^{\circledR}$ (version 9.3) statistical software. All tests were two-tailed with the probability of type I error at 0.05 . Our Institutional Review Board deemed this study to be exempt from its oversight.

\section{Results}

In total, we identified 2046 patients who met our inclusion criteria. Among these patients, 382 (18.7\%) were statin users. When compared with nonusers, patients on statin therapy were more likely to be older $(P<0.001)$ and men $(P<0.001)$ (Table 1). With regard to socioeconomic status, statin users were more likely to have full-time employment $(P<0.001)$, be salaried $(P=0.005)$, and have a more generous benefit plan $(P<0.005)$. They were also more likely to reside in the Midwest and Northeast $(P<0.005)$. Perhaps more important, a greater proportion of statin users had higher levels of comorbid illness and preoperative sepsis and UTI than nonusers $(P<0.001)$.

Postoperative sepsis was uncommon in our cohort, occurring in only $78(3.8 \%)$ of patients. In $10 \%$ of these patients, 
Table 1. Comparisons Between Patients Who Received Statin Therapy at the Time of Percutaneous Nephrolithotomy and Those Who Did Not

\begin{tabular}{|c|c|c|c|}
\hline \multirow[b]{2}{*}{ Patient characteristic } & \multicolumn{2}{|c|}{ Statin use } & \multirow[b]{2}{*}{$\mathrm{P}$ value } \\
\hline & Yes & No & \\
\hline No. of patients (\%) & $382(18.7)$ & $1664(81.3)$ & \\
\hline Patient age, mean (SD) & $55.6(7.2)$ & $47.6(10.9)$ & $<0.001$ \\
\hline$\%$ Male & 63.1 & 46.3 & $<0.001$ \\
\hline $\begin{array}{l}\% \text { Inpatient setting } \\
\text { procedure }\end{array}$ & 63.9 & 68.3 & 0.098 \\
\hline$\%$ Benefit plan type & & & $<0.001$ \\
\hline Comprehensive & 20.4 & 10.9 & \\
\hline $\mathrm{PPO}$ & 0.0 & 0.7 & \\
\hline HMO & 11.5 & 17.7 & \\
\hline POS & 9.7 & 11.9 & \\
\hline Other noncapitated & 58.4 & 58.7 & \\
\hline$\%$ Salaried & 22.3 & 16.2 & 0.005 \\
\hline $\begin{array}{l}\% \text { Full-time } \\
\text { employment }\end{array}$ & 54.3 & 41.6 & $<0.001$ \\
\hline$\%$ Urban & 75.7 & 77.6 & 0.403 \\
\hline \% Charlson score: & & & $<0.001$ \\
\hline 0 & 59.7 & 78.6 & \\
\hline 1 & 28.3 & 13.4 & \\
\hline 2 & 6.8 & 5.1 & \\
\hline$\geq 3$ & 5.2 & 2.9 & \\
\hline$\%$ Region of residence: & & & $<0.001$ \\
\hline Northeast & 9.4 & 9.0 & \\
\hline Midwest & 35.6 & 26.3 & \\
\hline South & 45.6 & 48.9 & \\
\hline West & 8.6 & 15.3 & \\
\hline Unknown & 0.8 & 0.5 & \\
\hline $\begin{array}{l}\% \text { Preoperative } \\
\text { antibiotic use }\end{array}$ & 5.2 & 4.3 & 0.440 \\
\hline $\begin{array}{l}\% \text { Preoperative sepsis } \\
\text { or UTIs }\end{array}$ & 69.6 & 60.3 & 0.001 \\
\hline $\begin{array}{l}\% \text { Preoperative use of } \\
\text { drainage tube }\end{array}$ & 5.8 & 8.5 & 0.077 \\
\hline
\end{tabular}

$\mathrm{SD}=$ standard deviation; $\mathrm{PPO}=$ preferred provider organization; $\mathrm{HMO}=$ health maintenance organization; $\mathrm{POS}=$ point of service; $\mathrm{UTI}=$ urinary tract infection

sepsis was severe enough to warrant ICU admission, but no deaths occurred in our cohort. More than $40 \%$ of sepsis events occurred in the first 3 days after PCNL (Fig. 1). Only 13\% of patients with sepsis had a drainage tube (either a ureteral stent or nephrostomy tube) inserted before the procedure. Patient factors that were independently associated with the odds of sepsis included the level of comorbid illness and whether or not the procedure was performed on an outpatient or inpatient basis (Table 2). On multivariable analysis, the occurrence of an uncomplicated UTI or sepsis before surgery increased the odds of postoperative sepsis by $71 \%$ (odds ratio [OR], 1.71; $95 \%$ confidence interval $[\mathrm{CI}], 1.06$ to $2.76 ; P=0.028$ ).

Statin use, however, was not associated with any protective effect against postoperative sepsis (OR, 1.61; 95\% CI, 0.91 to 2.86; $P=0.105)$. As shown in Figure 2, statin users had adjusted rates of postoperative sepsis comparable to those of nonusers (5.3\% vs 3.5\%, respectively; $P=0.105)$. In addition, UTI and ICU utilization rates also did not differ between statin users and nonusers $(P=0.113$ and $P=0.666$, respectively). Although the mean of hospital LOS was shorter in

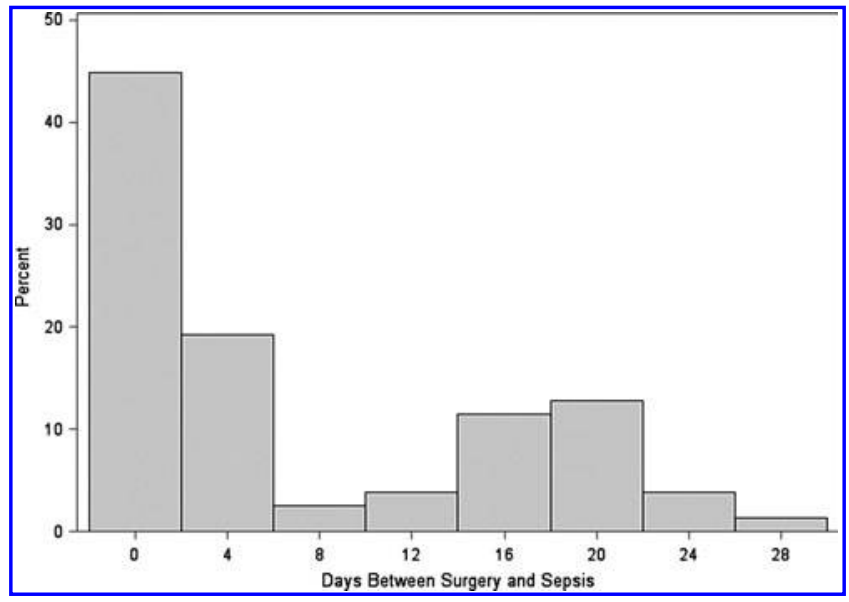

FIG. 1. The interval between surgery and a sepsis diagnosis.

favor of statin users, this difference was trivial clinically (3.6 vs 4.1 days; $P=0.007)$.

\section{Discussion}

We found that the use of a statin medication was not associated with reduced rates of sepsis after PCNL. UTI and ICU utilization rates also did not vary by statins use. While this class of medications may have other salutary effects on patient health, our collective findings do not support the use of statin medications for sepsis prophylaxis among PCNL patients.

One explanation for the lack of effect is because of insufficient statistical power. Therefore, we performed a post hoc power calculation to determine the minimum detectable effect size in our study. With 2046 patients in our cohort (382 statin users) and a 5\% type I error, we had $80 \%$ power to

Table 2. Multiple Logistic Regression Results for Postpercutaneous Nephrolithotomy Sepsis

\begin{tabular}{|c|c|c|c|}
\hline Patient characteristic & $O R$ & $95 \% C I$ & $\mathrm{P}$ value \\
\hline $\begin{array}{l}\text { Statin user } \\
\quad(\text { nonusers }=\text { referent })\end{array}$ & 1.61 & 0.91 to 2.86 & 0.105 \\
\hline Female $($ male $=$ referent $)$ & 1.15 & 0.70 to 1.87 & 0.586 \\
\hline Age & 0.98 & 0.96 to 1.01 & 0.108 \\
\hline $\begin{array}{l}\text { Inpatient setting } \\
\quad \text { (outpatient }=\text { referent })\end{array}$ & 2.31 & 1.27 to 4.17 & 0.006 \\
\hline \multicolumn{4}{|l|}{$\begin{array}{l}\text { Charlson score } \\
(\geq 3=\text { referent })\end{array}$} \\
\hline 0 & 0.38 & 0.14 to 1.0 & 0.013 \\
\hline 1 & 0.74 & 0.26 to 2.11 & 0.370 \\
\hline 2 & 0.99 & 0.31 to 3.21 & 0.260 \\
\hline $\begin{array}{l}\text { Preoperative antibiotic use } \\
\text { (no antibiotics = referent) }\end{array}$ & 0.85 & 0.29 to 2.42 & 0.769 \\
\hline $\begin{array}{l}\text { Preoperative sepsis/UTI } \\
\text { (no preoperative sepsis } \\
\text { events/UTIs = referent) }\end{array}$ & 1.71 & 1.06 to 2.76 & 0.028 \\
\hline $\begin{array}{l}\text { Preoperative drainage tube } \\
\quad \text { (no drainage tube }=\text { referent })\end{array}$ & 1.77 & 0.87 to 3.58 & 0.115 \\
\hline
\end{tabular}

$\mathrm{OR}=$ odds ratio $\mathrm{CI}=$ confidence interval . 


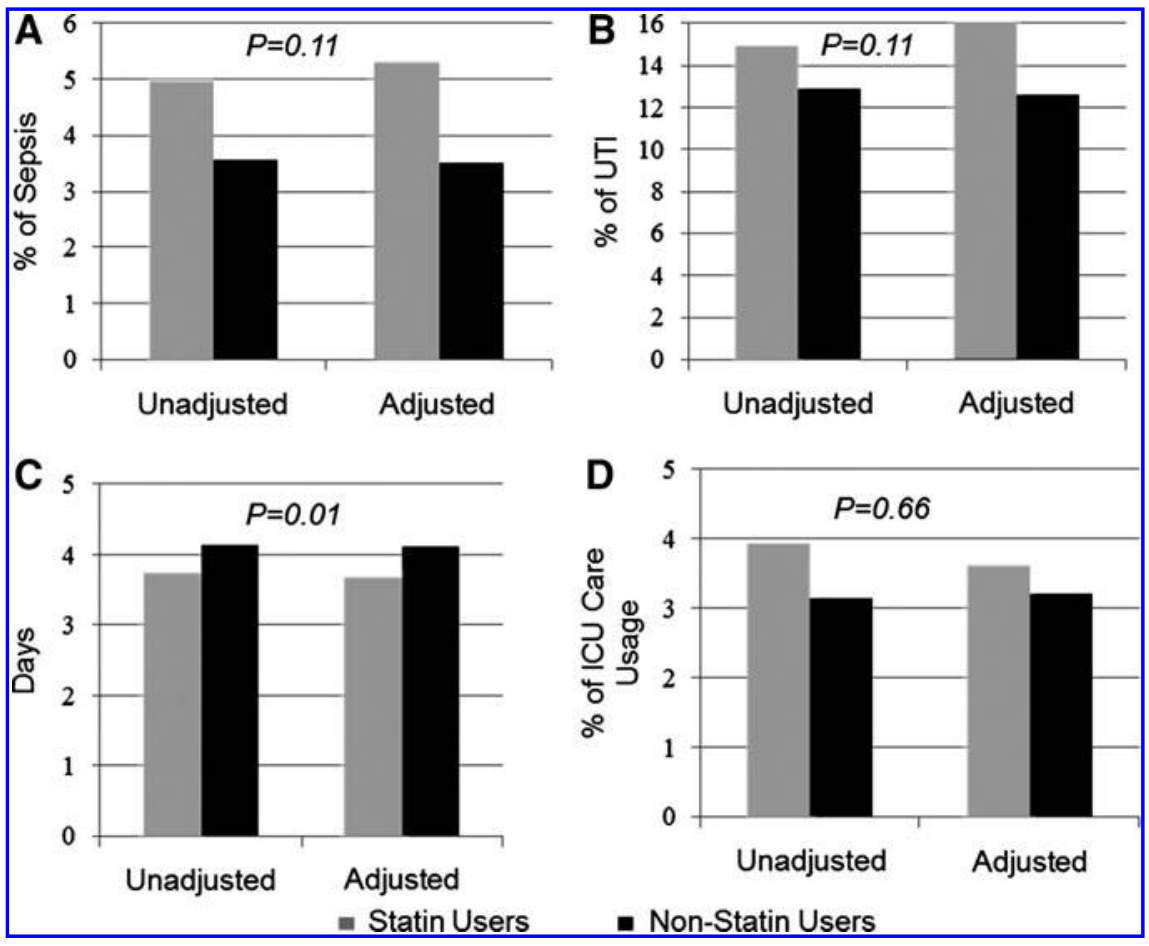

FIG. 2. Statin outcomes. (A) Postpercutaneous nephrolithotomy (PCNL) sepsis rate; (B) Post-PCNL urinary tract infection (UTI). (C) Length of stay for PCNL patients; (D) Intensive care unit (ICU) care usage post-PCNL. detect a $50 \%$ reduction in rate of sepsis between our treatment and comparison groups. We observed, however, in both unadjusted and adjusted models, a higher rate of sepsis in our statin user group. Therefore, we are not worried about insufficient power to detect a clinically meaningful reduction in sepsis rate.

Our study is not the first one to call into question the statin utility for decreasing the infectious complications in medical or surgical patients, however. ${ }^{23-25}$ In a recent meta-analysis, pooled data from 11 trials reporting on the incidence of infection among statin users found that statin use had no effect on infection risk. ${ }^{26}$ Moreover, among patients who underwent cardiac surgery, Trezzi and associates ${ }^{27}$ found no significant difference in the rate of postoperative infection in patients who were receiving statins $(4.3 \%)$ compared with patients who were not receiving statins $(3.8 \%)$.

Data from our study highlighted some patient-specific factors that were associated with sepsis: The level of comorbidity, a history of previous sepsis or UTI, and the ambulatory status of the procedure. Clinicians could use this information when counseling patients on their sepsis risk. We did not find any statistically significant association between sepsis and age, sex, preoperative antibiotic use, or insertion of a drainage tube before the surgical procedure.

There are several limitations to our study. First, because of the observational nature of our study, the potential for residual confounding exists. Second, while we accounted for many patient-level variables associated with sepsis as well as validated measures of comorbidities (the Charlson index), certain factors, such as obesity, stone type, and procedure duration, may impact a patient's sepsis risk and are not measurable using sources of administrative data. Third, our patient cohort was limited to working-age adults with insurance. While this population may limit the external validity of our results, it is important to note that this subgroup represents the one most commonly affected by urinary stone disease. ${ }^{28}$
Finally, one limitation of working with claims data is that we know whether or not the patients filled the prescription but do not know if the patient actually took the medication as prescribed. It is possible that issues related to a patient's noncompliance with prescribed therapy could affect our results. That being said, drug information from MarketScan database is widely used. ${ }^{29}$

Notwithstanding these limitations, our study has clinical implications for the treatment of patients undergoing PCNL. While statin therapy may not be beneficial, there are compelling data on the utility of intraoperative renal pelvis urine cultures and stone cultures for predicting postoperative sepsis. ${ }^{30}$ Given our findings, urologists who perform PCNL would be better served by directing their attention to tests like these, specifically for the patients with high comorbidities and previous history of UTIs. Moreover, there may be a role for clinical care pathways, which may aid in the early recognition and management of sepsis, thereby lowering its associated morbidity and mortality.

\section{Conclusions}

Our study does not support the use of statins for decreasing the risk of sepsis in patients undergoing PCNL. Urologists who care for patients with urinary stone disease should focus their attention on other processes of care to prevent sepsis in this population.

\section{Acknowledgment}

Supported by the Agency for Healthcare Research and Quality Grant 1K08HS020927 01A1 (JMH).

This article was published as an abstract-Abstract \# MP09-07: J Endourol 2014;28(suppl 1):P1-A316.

\section{Author Disclosure Statement}

No competing financial interests exist. 


\section{References}

1. de la Rosette J, Assimos D, Desai M, et al. The Clinical Research Office of the Endourological Society Percutaneous Nephrolithotomy Global Study: Indications, complications, and outcomes in 5803 patients. $\underline{\mathrm{J} \text { Endourol }}$ 2011;25:11-17.

2. Labate G, Modi P, Timoney A, et al. The percutaneous nephrolithotomy global study: Classification of complications. J Endourol 2011;25:1275-1280.

3. O'Keeffe NK, Mortimer AJ, Sambrook PA, Rao PN. Severe sepsis following percutaneous or endoscopic procedures for urinary tract stones. Br J Urol 1993;72:277-283.

4. de la Rosette J, Denstedt J, Geavlete P, et al. The clinical research office of the endourological society ureteroscopy global study: Indications, complications, and outcomes in 11,885 patients. J Endourol 2014;28:131-139.

5. Hong JY, Yang SC, Ahn S, Kil HK. Preoperative comorbidities and relationship of comorbidities with postoperative complications in patients undergoing transurethral prostate resection. J Urol 2011;185:1374-1378.

6. Mirheydar HS, Palazzi KL, Derweesh IH, et al. Percutaneous nephrolithotomy use is increasing in the United States: An analysis of trends and complications. J Endourol 2013;27:979-983.

7. Albert MA, Danielson E, Rifai N, Ridker PM; PRINCE Investigators. Effect of statin therapy on C-reactive protein levels: The pravastatin inflammation/CRP evaluation (PRINCE): A randomized trial and cohort study. JAMA 2001;286:64-70.

8. Terblanche M, Almog Y, Rosenson RS, et al. Statins and sepsis: Multiple modifications at multiple levels. Lancet Infect Dis 2007;7:358-368.

9. Vollmer T, Key L, Durkalski V, et al. Oral simvastatin treatment in relapsing-remitting multiple sclerosis. Lancet 2004;363:1607-1608.

10. Ridker PM, Rifai N, Clearfield M, et al. Measurement of C-reactive protein for the targeting of statin therapy in the primary prevention of acute coronary events. N Engl J Med 2001;344:1959-1965.

11. Weitz-Schmidt G, Welzenbach K, Brinkmann V, et al. Statins selectively inhibit leukocyte function antigen-1 by binding to a novel regulatory integrin site. Nat Med 2001;7:687-692.

12. Janda S, Young A, Fitzgerald JM, et al. The effect of statins on mortality from severe infections and sepsis: A systematic review and meta-analysis. J Crit Care 2010;25:656 e7-22.

13. Almog Y, Novack V, Eisinger M, et al. The effect of statin therapy on infection-related mortality in patients with atherosclerotic diseases. Crit Care Med 2007;35:372-378.

14. Coleman CI, Lucek DM, Hammond J, White CM. Preoperative statins and infectious complications following cardiac surgery. Curr Med Res Opin 2007;23:1783-1790.

15. Gupta R, Plantinga LC, Fink NE, et al. Statin use and sepsis events [corrected] in patients with chronic kidney disease. JAMA 2007;297:1455-1464.

16. Hackam DG, Mamdani M, Li P, Redelmeier DA. Statins and sepsis in patients with cardiovascular disease: A population-based cohort analysis. Lancet 2006;367:413-418.

17. Litwin MS, Saigal CS, Yano EM, et al. Urologic diseases in America Project: Analytical methods and principal findings. J Urol 2005;173:933-937.

18. Semins MJ, Trock BJ, Matlaga BR. Validity of administrative coding in identifying patients with upper urinary tract calculi. J Urol 2010;184:190-192.
19. U.S. Food and Drug Administration: National Drug Code Directory. Available at: http://www.accessdata.fda.gov/ scripts/cder/ndc/default.cfm Accessed: February 10, 2014.

20. Plenge JK, Hernandez TL, Weil KM, et al. Simvastatin lowers C-reactive protein within 14 days: An effect independent of low-density lipoprotein cholesterol reduction. Circulation 2002;106:1447-1452.

21. Sammon JD, Ghani KR, Karakiewicz PI, et al. Temporal trends, practice patterns, and treatment outcomes for infected upper urinary tract stones in the United States. Eur Urol 2013;64:85-92.

22. Klabunde CN, Potosky AL, Legler JM, Warren JL. Development of a comorbidity index using physician claims data. J Clin Epidemiol 2000;53:1258-1267.

23. Becker K, Tanzi P, Kalil A, et al. Early statin use is associated with increased risk of infection after stroke. J Stroke Cerebrovasc Dis 2013;22:66-71.

24. Fernandez R, De Pedro VJ, Artigas A. Statin therapy prior to ICU admission: Protection against infection or a severity marker? Intensive Care Med 2006;32:160-164.

25. Kruger P, Bailey M, Bellomo R, et al. A multicenter randomized trial of atorvastatin therapy in intensive care patients with severe sepsis. Am J Respir Crit Care Med 2013; 187:743-750.

26. van den Hoek HL, Bos WJ, de Boer A, van de Garde EM. Statins and prevention of infections: Systematic review and meta-analysis of data from large randomised placebo controlled trials. BMJ 2011;343:d7281.

27. Trezzi M, Blackstone EH, Sun Z, et al. Statin therapy is associated with fewer infections after cardiac operations. Ann Thorac Surg 2013;95:892-900.

28. Scales CD, Jr., Smith AC, Hanley JM, Saigal CS, Urologic Diseases in America Project. Prevalence of kidney stones in the United States. Eur Urol 2012;62:160-165.

29. Hansen LG, Chang S. Health Research Data for the Real World: The MarketScan Database. Ann Arbor: Thomson Medstat. 2012.

30. Kreydin EI, Eisner BH. Risk factors for sepsis after percutaneous renal stone surgery. Nat Rev Urol 2013;10:598605 .

Address correspondence to:

John M. Hollingsworth, MD, MS Department of Urology University of Michigan Medical School North Campus Research Complex 2800 Plymouth Road

Building 16, 1st Floor, Room $113 \mathrm{~W}$

Ann Arbor, MI 48109-2800

E-mail: kinks@med.umich.edu

\begin{aligned} & \multicolumn{1}{c|}{ Abbreviations Used } \\ & $\mathrm{CI}=$ confidence interval \\ & $\mathrm{ICD}-9=$ International Classification of Diseases \\ & Ninth Revision, Clinical Modification \\ & $\mathrm{ICU}=$ intensive care unit \\ & $\mathrm{LOS}=$ length of stay \\ & $\mathrm{OR}=$ odds ratio \\ & $\mathrm{PCNL}=$ percutaneous nephrolithotomy \\ & $\mathrm{UTI}=$ urinary tract infection \end{aligned}


This article has been cited by:

1. Daniel A. Wollin, Adrian D. Joyce, Mantu Gupta, Michael Y. C. Wong, Pilar Laguna, Stavros Gravas, Jorge Gutierrez, Luigi Cormio, Kunjie Wang, Glenn M. Preminger. 2017. Antibiotic use and the prevention and management of infectious complications in stone disease. World Journal of Urology 35:9, 1369-1379. [Crossref]

2. Leow Jeffrey J., Meyer Christian P., Wang Ye, Chang Steven L., Chung Benjamin I., Trinh Quoc Dien, Korets Ruslan, Bhojani Naeem. 2017. Contemporary Trends in Utilization and Perioperative Outcomes of Percutaneous Nephrolithotomy in the United States from 2003 to 2014. Journal of Endourology 31:8, 742-750. [Abstract] [Full Text HTML] [Full Text PDF] [Full Text PDF with Links] 